DOI 10.37882/2223-2982.2020.04-2.31

\title{
ПРОДВИЖЕНИЕ ИНТЕРНАЦИОНАЛИЗАЦИИ МАГИСТЕРСКИХ ПРОГРАММ: СТРАТЕГИИ, СРЕДСТВА И КАНАЛЫ КОММУНИКАЦИИ
}

\section{THE ADVANCE OF INTERNATIONALIZATION OF MASTER PROGRAMS: STRATEGY, MEANS AND COMMUNICATION CHANNELS}

Song $Y u$

Summary: The internationalization of higher education has gone beyond the level of education policy and has risen to the national development strategy. Currently in the development of external education has been a popularization, internationalization master's education. master's education takes an important place in the system of higher education. Use of master's education contributes to development of higher education system, cooperation in the sphere of general education and includes various student exchange programs. It is only natural for many universities around the world to pay close attention to development of master programs. The development of science and technology has also introduced more concepts, means and channels of advancing for higher education. To use these methods, it is possible to create a broader global education market that will enrich the future of higher education.

Keywords: internationalization of higher education, educational program, strategy, means, communication channels.

\section{Введение}

И нтернационализация - это будущее высшего образования. Сейчас подготовке магистерских программ уделяют особое внимание во многих университетах по всему миру. В условиях серьезной конкуренции между ВУЗами предложение образовательных программ требует соответствующего информационного сопровождения. Применение PR-концепций, средств и каналов продвижения способствуют не только укреплению репутации университетов, но и переходу высшего образования на глобальный уровень. В данной статье предпринимается попытка определить стратегии и методы продвижения магистерских программ на мировом рынке образовательных услуг. Стоит отметить, что ключевой задачей образования является способствование интеллектуально-культурному развитию общества; использование механизмов продвижение для сферы образования представляется необходимым инструментом в условиях рыночной экономики.

С этой целью в статье предлагается общее описание
Сун Юй

Аспирант, Московский государственный университет имени М.В. Ломоносова

135845292@mail.ru

Аннотация: Интернационализация высшего образования вышла за рамки политики в области образования и достигла уровня национальной стратегии развития. В настоящее время в развитии высшего образования, магистратура занимает важное место. Применение магистерского образования способствует развитию системы высшего образования, сотрудничеству в общеобразовательной сфере и включает многочисленные программы академической мобильности. Вполне естественно, что во многих университетах мира разработке магистерских программ уделяется пристальное внимание. Развитие науки и техники вызвало появление новых концепций, средств и каналов продвижения высшего образования, которые позволяют сегодня формировать глобальный рынок образования.

Ключевые слова: интернационализация высшего образования, образовательная программа, стратегия, средства, каналы коммуникации.

образовательных программ магистратуры; описываются стратегии, средства и каналы коммуникации для продвижения программ ряда университетов.

В условиях роста конкуренции на международном рынке образовательных услуг интернационализация системы высшего образования и привлечение большего числа иностранных студентов продолжает оставаться важной стратегической задачей. Особую значимость она приобретает для региональных опорных вузов. При этом особое внимание уделяется профессиональным навыкам адаптации и медиации, владение которыми является принципиально важным для эффективного взаимодействия с иностранными студентами.

В своих работах авторы анализируют трудности, с которыми сталкиваются преподаватели гуманитарных дисциплин при выполнении такой работы, и предлагаются возможные способы их решения. Однако работы, посвященные PR-стратегиям укрепления репутации университетов и продвижения образовательных программ на международном уровне, отсутствуют. 


\section{Стратегии продвихкения образовательных программ}

Степень магистра является важной ступенью в подготовке специалистов. Магистерская программа позволяет углубить специализацию в конкретной профессии, специалисты с магистерской степенью востребованы и в исследовательских и образовательных учреждениях, и в бизнес-структурах.

Для современного магистерского образования в ВУЗах актуальным стал вопрос ведения научно-исследовательской деятельности магистрантов. Сейчас научно-исследовательская деятельность магистрантов считается ключевым фактором улучшения рейтинга университе$\mathrm{Ta}[9]$.

В теории маркетинга есть три разные стратегии продвижения товаров и услуг на рынках, включая внешние, которые применимы и к образовательным программам:

- Недифференцированный маркетинг - стратегия продвижения единых образовательных программ для всех сегментов рынка с целью сформировать образ высокого качества услуг. Используются универсальные маркетинговые инструменты.

- Дифференцированный маркетинг - стратегия формирования разных образовательных программ с учетом продвижения одновременно на разных сегментах рынка с целью упрочить в этих сегментах собственные позиции и обеспечить спрос на новые и существующие образовательные продукты. Используются уникальные, разработанные для каждого предложения, инструменты продвижения.

- Концентрированный маркетинг реализуют у себя вузы при условии ограниченности имеющихся ресурсов, отбирают похожие сегменты по разным субрынкам, подготавливая для них особые унифицированные программы продвижения [10, с. 8-11].

\section{Стратегии продвижение образовательных программ интернационального характера}

В продвижении магистерских программ интернационального характера применяются стратегии «наступления» и стратегии «обороны».

Стратегии «наступления» на рынке образования характерны для молодых «агрессивных» образовательных заведений, которые пользуются существенной поддержкой государства, крупных компаний и финансовых организаций. К примеру, Гонконгский университет науки и технологии основан в 1991 году, в 2018 в университете обучалось 10214 студентов, треть (31\%) из них иностранные студенты, осваивающие различные высококачественные программы образования, что позволяет университету конкурировать с традиционными крупными зарубежными университетами [8].

Гонконгский университет науки и технологии имеет серьезную глобальную репутацию в сфере научных исследований. Будучи молодым университетом, он продвигает свои собственные международные образовательные бренды не только в Азии, но и в мире, предоставляя гуманизированные услуги для студентов из разных стран и регионов. А также предоставляет студентам возможность самостоятельно выбирать программы обучения. Это позволило Гонконгскому университету науки и технологии занять первое место в рейтинге "Young University Rankings 2018". Этот университет планирует в ближайшие 25 лет стать более интернациональным и в большей степени распространить свое влияние в регионах. Стратегия развития Гонконгского университета науки и технологии хорошо показывает, как стратегия «наступления» может способствовать включению в рейтинги университетов. Такой феномен предусматривает агрессивную, активную позицию университетов на международном образовательном рынке, что позволяет добиться завоевания и расширения рыночной доли.

Реализация стратегии «обороны» заключается в усилении рыночных позиций предприятий, которые не расходуют ресурсы на создание услуги, либо по различным причинам терпели неудачи в предложении главных услуг. Стратегия обороны и укрепления помогает образовательной организации сохранить рыночные позиции, а также предполагает выбор учреждением курса на сохранение текущей рыночной доли. Потребность в такой стратегии появляется тогда, когда рыночная позиция учреждения удовлетворительная, либо у неё имеется дефицит денег для реализации агрессивной политики, либо когда она боится реализовать последнюю в связи с вероятными негативными ответными действиями конкурентов или барьерами государства [2].

Например, когда университету не хватает финансовой поддержки, или существующая стратегия не дает ожидаемых результатов, или другие факторы приводят к снижению репутации университета, в качестве чрезвычайной меры стоит использовать стратегию обороны, чтобы удержать рыночную долю и получить время для корректировки стратегий.

В настоящее время многие вузы занимаются формированием стратегии и тактики маркетинговой и коммуникационной деятельности наряду с разносторонним техническим развитием.

Пресс-служба каждого вуза выполняет важную функцию в продвижении его образовательных программ. Многие университеты активно рекламируют эти про- 
граммы в медиапространстве. В то же время необходимо отметить, что продвижение магистерских программ в пространстве массмедиа весьма затратно и не во всех случаях ведёт к достижению желаемых целей. В подобных условиях имеет смысл использовать разные информационные ресурсы, сформированные на основе прессслужбы университета [4].

У ВУЗов во многих странах назрела потребность в создании и продвижении интернациональных образовательных, в том числе магистерских, программ., но не все способны занять достойную позицию на рынке международных образовательных услуг [9]. Причины этому разные и очень важна государственная поддержка. К примеру, в 2015-2017 годах национальный бюджет в Китае составил $4.26 \%-4.22 \%-4.14 \%$, а в США - больше чем $6 \%$.

Университеты, лишенные государственной поддержки, вынуждены считаться с приоритетами принимающей приоритеты и условиями иностранных партнёров даже если преподаватели ВУЗа имеют высокую квалификацию, потому что ВУЗ может не иметь достаточного финансового обеспечения для гарантии минимальной мобильности собственных студентов, принятия иностранных и качественного реагирования на различные запросы текущего рынка образовательных услуг[1].

С другой стороны, обучение зарубежных студентов приносит бюджетам стран всего мира значительный доход, в связи с этим усиливается конкуренция и всё активнее говорят о себе новые участники международного рынка образовательных услуг - Китай, Австралия, Япония, Канада. Так, в Китае за 2010-2014 годы открылось свыше 100 новых университетов, что позволяет постоянно увеличивать количество иностранных студентов [9]. Поэтому у некоторых развивающихся университетов возникла потребность в создании и продвижении специальных двусторонних магистерских программ, ориентированных на приток зарубежных студентов и взаимодействие с традиционными известными ВУЗами в мире, чтобы повысить популярность своих услуг на мировом образовательном рынке.

Помимо этого, в России получила слабое развитие практика дистанционного обучения, что тоже тормозит продвижение разных магистерских программ.

Следует отметить, что при анализе средств и инструментов продвижения магистерских программ в российских ВУЗах полагаются на мировой опыт, т.к. США, государства из Европы и Китай уже довольно давно используют комплексный подход к продвижению такого рода услуг, причём подход этот, в первую очередь, основывается на исследовании целевой аудитории [3].

\section{Инструменты продвижения интернашиональных магистерских программ}

Основой продвижения разных магистерских программ выступают, конечно же, коммуникации в сети Интернет. В то же время каналы продвижения в интернете в значительной степени зависят от того, какую конкретно целевую аудиторию выбирают в виде базовой.

К самым важным и нужным для каждой целевой группы способам коммуникации относятся такие:

1. Университетский сайт на 2-3 языках с разными инструментами продвижения в виде информативного рубрикатора, интуитивно понятной навигации и максимально удобным поиском по сайту.

2. Обособленный двуязычный лендинг по разным магистерским программам, с разными инструментами в виде рабочих действующих ссылок, «консультационного окна» или специализированного каталога магистерских программ на 2-3 языках, где можно заняться поиском по разным фильтрам, записью через интернет на привлекающие внимание программы и просмотром содержания таких программ.

3. Сайты-партнёры для размещения публикации о различных магистерских программах на 2-3 языках.

4. Социальные сети: Вконтакте, Facebook и Twitter, LinkedIn, Instagram или Pinterest, YouTube.

5. Образовательные выставки, семинары и научные конференции.

6. Формальные и неформальные студенческие объединения, и инструментом здесь выступают данные о магистерских программах, размещённые в их постах.

7. Особые мероприятия и дни для специального тестового ознакомления с разными магистерскими программами, в том числе и дистанционно. Так, к примеру, в Высшей школе экономики есть особая программа «Learning Management System», помогающая потенциальным студентам познакомиться с особенностями обучения на магистерских программах в Высшей школе экономики.

8. Рекрутинговые студенческие сайты: Study in Europe, Minglebox, EURUEDUNET, MASTERSTUDIES. COM, EuroEducation.net.

9. Личные коммуникации разных представителей административно-управленческих работников университетов [6, с.20].

Например, сейчас во многих российских вузах разработают специальные магистерские программы для привлечения студентов из Китая, их родителей и рекрутинговых китайских компаний. Источником сведений о магистерских программах, как правило, является официальный сайт ВУЗа. Также пользователи обращают особое 
внимание как на сведения, так и на структуру сайта, уровень удобства навигации по сайту [3]. Для иностранных студентов первое впечатление о самом ВУЗе складывается как раз по сайту, т.к. нередко они изучают несколько вариантов в различных странах, т.е. не приходят в каждое из рассматриваемых учебных учреждений [7].

Важным способом продвижения оказывается мобильный вариант сайта ВУЗа, который в значительной мере отличается от обычной версии для компьютера.

В подобной мобильной вариации сайта в обязательном порядке должен иметься раздел «Магистратура» с единым каталогом магистерских программ и детальными сведениями на разных языках с удобным поиском. Во время выхода на рынки европейские ВУЗы намеренно разрабатывают видео-блоги, где детально рассматриваются отдельные составляющие магистерских программ, что помогает наглядно показать зарубежному студенту преимущества дистанционного прохождения магистерской программы и преимущества определённого учебного учреждения и его подхода к процессу обучения. В мобильном варианте сайта указанные видео и рекламные блоки реализованы на основе Google Play и App Store. В отдельных развивающихся государствах создание мобильных версий сайта и видео-блогов пока ещё не очень распространено, но данные средства уже постепенно становятся популярными [5].

Вспомогательным инструментом в области продвижения магистерских программ являются рекрутинговые студенческие сайты, так как предоставляют возможность разместить сведения о магистерских программах. Эффективность рекрутинговых сайтов уже получила подтверждение тем, что многие ВУЗы размещают на них свои данные, добиваясь наибольшего отклика [5]. Магистратура - это лишь один из значительных образовательных ресурсов.

Важным средством продвижения считается также рассылка данных о магистерских программах в форме информационного письма в организации-партнёры (то есть ВУЗы и научно-исследовательские центры) за границей, в выездные приёмные комиссии, что позволяет привлечь зарубежных студентов. Эта методика давно и успешно используется в Европе и США, где привлекают студентов из различных университетов к реализации совместных программ [9].

Представление разных магистерских программ ВУЗов на особых ярмарках и выставках образовательного и студенческого направления, научных семинарах и конференциях - это ещё один эффективный инструмент продвижения и интернационализации магистерских программ. Подобный опыт применяется китайскими ВУЗами с целью привлечения студентов из России, и соот- ветственно, является актуальным для России.

Интересным способом продвижения разных магистерских программ считаются разные «Дни открытых дверей». При этом международный опыт является примером проведения подобных мероприятий через интернет, что даёт возможности для организации продвижения разных образовательных услуг. Например, в Германии подобный способ продвижения использует университет Фрайбурга, где особое внимание уделено разным программам магистерского «гостевого» (вольнослушательского) обучения, включённого в цикл непрерывного образования (Universitäre Weiterbildung). Подобное обучение позволяет сделать университет открытым для всего мира, а материалы и онлайн-лекции предлагаются студентам через, особым образом, подготовленные электронные платформы. Не столь важно, где именно оказывается студент, т.к. за счёт онлайн-общения он напрямую вовлекается в образовательный процесс в режиме реального времени [5].

Во время выхода магистерских программ на иностранный рынок нередко пользуются агентским продвижением, в контексте которого агент адаптирует определённую магистерскую программу для определённых требований и условий национального рынка, подготавливает рекламную продукцию, осуществляет распространение её в СМИ, в приёмных комиссиях ВУЗов важной для заказчика страны, полагаясь на традиции и особенности данного региона [3].

Результаты исследования показали, что национальный бюджет на образование является основой базой для развития образования. Стратегия наступления оказывает большое влияние на молодые университеты, которые стремятся к созданию и укреплению международной репутации. Различные современные сетевые платформы также способствуют продвижению магистерских программ собственных университетов на международный рынок образовательных услуг. Если университет совершает стратегические ошибки, сохранить рыночные позиции помогает ему стратегия обороны.

\section{Выводы}

Итак, можно сделать вывод, что интернационализация магистерского образования набирает обороты. С развитием современной науки и техники развиваются и каналы коммуникации, и средства продвижения интернациональных магистерских программ. Доминирующее положение занимают средства продвижения в сети Интернет. С одной стороны, это более удобный и быстрый способ обмена информацией между университетами и целевыми аудиториями в разных странах, с другой стороны, он может активно содействовать формированию международных стандартов для интернаци- 
онализации магистерского образования. Сочетание новой технологии и традиционных методов продвижения образовательного учреждения предоставляет новые возможности многим развивающимся университетам.
Международный рынок магистерского образования перестает быть монополией для некоторых традиционных известных университетов и предоставляет студентам более качественный выбор.

\section{ЛИТЕРАТУРА}

1. Арсеньев Д.Г., Алексанков А.М, Джаим Е.А. Маркетинг в международной деятельности вузов . СПб.2014.

2. Белоновская, И., С. Голошумова. Маркетинг в образовании: учебное пособие для студентов вузов, обучающихся по специальности «Профессиональное обучение [по отраслям]. СПб.:Питер,2010.

3. Боревская, Н.Е. Интернационализация российских вузов: китайский вектор. Российский совет по международным делам [РСМД]. - Москва: Спецкнига, 2013.

4. Громова, Л.А. Диалоговая функция PR в образовании. Сборник материалов конференции. СПб.: Питер ,2002.

5. Дубровская В.С., Калачикова 0.Н., Карнаухова Н.В., Краснова Г.А., Можаева Г.В., Нужина Н.И., Рыльцева Е.В., Сербин В.А., Трубникова Т.В., Фещенко А.В., Щеголева Н.В. Методика создания и внедрения магистерских программ с модулями в виде дистанционных курсов с участием иностранных профессоров. Томск, 2015.

6. Захарова Е.А. Проблемы эффективности маркетинговой деятельности в сфере высшего образования// Экономика и менеджмент инновационных технологий- 2013. -№4, С,20.

7. Покровский, Н.Е. 0 перспективах университетского образования в условиях глобализации. ГУ-ВШЭ, 2011.

8. Список данных Гонконгского университета науки и технологии. https://www.ust.hk/zh-hans/about-hkust/hkust-at-a-glance/facts-figures-2/ [дата обращение 20.10.2018]

9. Сяо Хайтао. Концепция университета /пер. с китайского. У Хань, 2001

10. Юрченко Н.А., Ворожбит 0.Ю., Осипов В.А. Управление продвижением российских образовательных услуг на внешний рынок на основе инновационных стратегий/Научный вестник Современные исследования социальных проблем.-2012.- № 12. с. 8-11

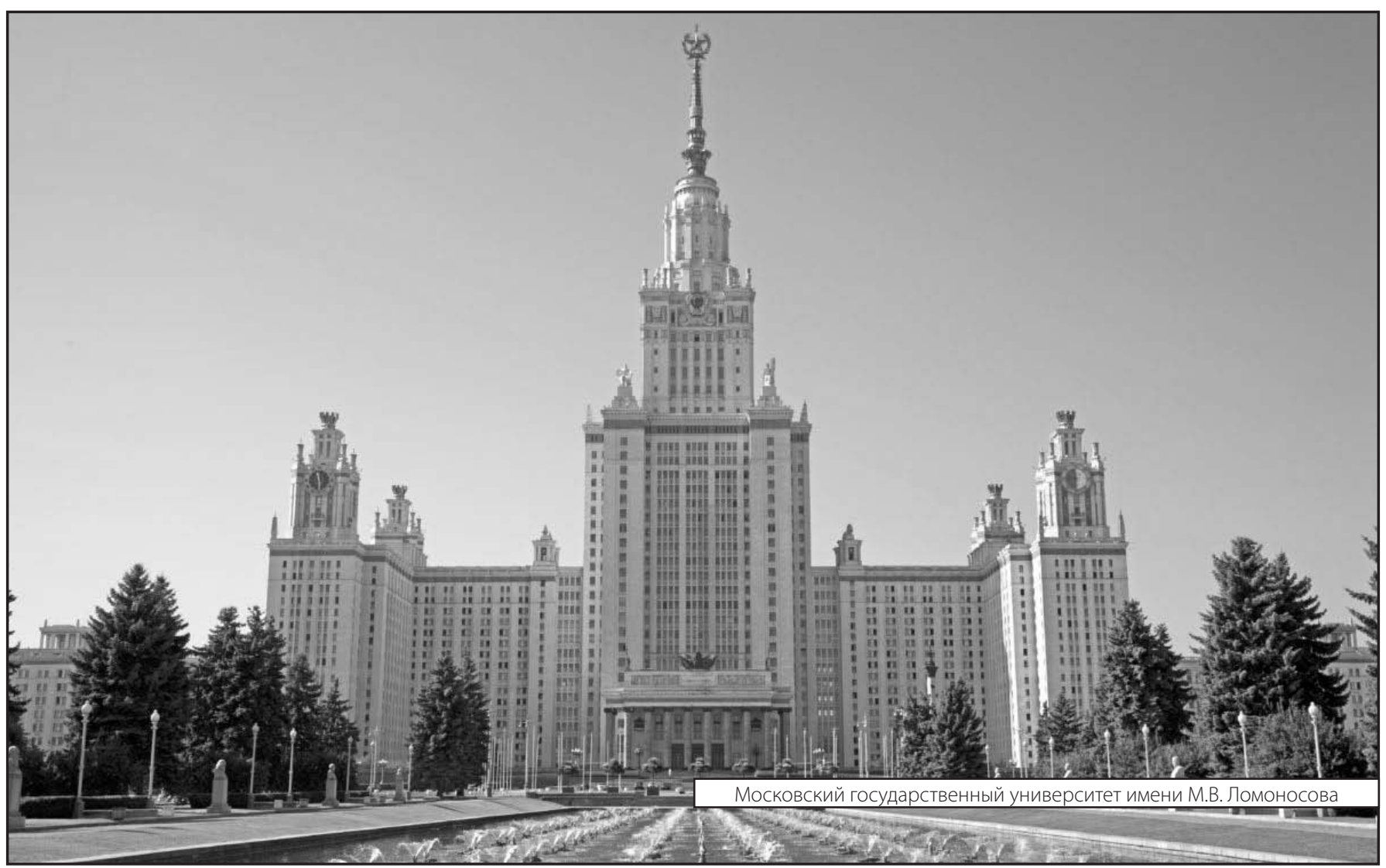

